\title{
Growth of Calcium Carbonate in the Presence of $\mathrm{Cr}(\mathrm{VI})$
}

\author{
Nuria $S^{\prime}$ anchez-Pastor, ${ }^{*,+,}$ Alexander M. Gigler, ${ }^{+, \S}$ Juncal A. Cruz, ${ }^{\ddagger}$ So-Hyun Park, ${ }^{\dagger}$ Guntram Jordan, ${ }^{\dagger}$ and \\ Lurdes Fern' andez-Díaz ${ }^{\ddagger} \|$ \\ ${ }^{\dagger}$ Department f" ur Geo- und Umweltwissenschaften, Ludwig-Maximilians-Universit" at, Theresienstrasse 41, 80333 Munich, Germany \\ ${ }^{\ddagger}$ Departamento de Cristalografía y Mineralogía, Universidad Complutense de Madrid, C/ Jose' Antonio Nov' ais 2, 28040 Madrid, \\ Seaintêr for NanoScience (CeNS), Ludwig-Maximilians-Universit" at, Schellingstrasse 4, 80333 Munich, Germany \\ "Instituto de Geociencias (UCM-CSIC), C/ Jose' Antonio Nov' ais 2, 28040 Madrid, Spain
}

\begin{abstract}
The extended use of hexavalent chromium $\mathrm{Cr}(\mathrm{VI})$ compounds in industrial processes caused a significant increase of the concentration of this highly toxic heavy metal in natural environments. In order to investigate the influence of $\mathrm{Cr}(\mathrm{VI})$ in the formation of $\mathrm{CaCO}_{3}$, crystallization experiments were carried out in a double diffusion system, using silica hydrogel with different $\mathrm{Cr}(\mathrm{VI})$ contents as the growth medium. Crystalline products were examined by scanning electron microscopy, Raman spectroscopy, electron microprobe analysis, and single crystal X-ray diffraction. Increasing $\mathrm{Cr}(\mathrm{VI})$ concentration caused inhibition of the nucleation and growth of calcite and promoted the formation of the metastable polymorphs aragonite and vaterite. This effect correlated with a decrease of crystal size. Furthermore, the habit of calcite crystals changed with increasing $\mathrm{Cr}(\mathrm{VI})$ concentrations from $\{104\}$ to forms increasingly elongated parallel to the $c$-axis. Raman spectroscopy, single crystal X-ray diffraction (XRD), and electron microprobe analysis (EMPA) gave strong indications of an isomorphic anion substitution of trigonal planar

carbonate by the tetrahedral chromate within the calcite lattice. The apparent partitioning coefficients of $\mathrm{Cr}(\mathrm{VI})$ into calcite determined in this work suggest that the fate of this pollutant in natural environments can be significantly influenced by $\mathrm{CaCO}_{3}$ precipitation processes.
\end{abstract}

\section{INTRODUCTION}

Hexavalent chromium is among the most harmful heavy metals due to its mutagenic and carcinogenic properties. The extended use of $\mathrm{Cr}(\mathrm{VI})$ compounds in many industrial processes during the last century has led to a significant increase of $\mathrm{Cr}$ concentration in natural environments, where it locally even exceeds safety limits. ${ }^{1} \mathrm{Cr}(\mathrm{VI})$ interacts with its chemical environment. It has been demonstrated that harmful metals can incorporate into the structure of sparingly soluble salts during growth. $^{2-7}$ Such an incorporation might also have a significant positive influence on the mobility of $\mathrm{Cr}(\mathrm{VI})$ and may contribute to the long-term reduction of its bioavailability.

Several research groups have studied the crystallization of $\mathrm{CaCO}_{3}$ in the presence of chromate. Hua et al. ${ }^{8}$ observed that $\mathrm{CaCO}_{3}$ which precipitated from chromate-bearing aqueous solution consists of a higher proportion of metastable polymorphs than $\mathrm{CaCO}_{3}$ formed in a pure system without chromium. On the basis of X-ray absorp-tion near edge structure (XANES) and extended X-ray absorption fine structure (EXAFS), Tang et al. ${ }^{9}$ concluded that chromate can substitute for carbonate within the calditetblisumork, we explore the role of chromate in the crystallization of $\mathrm{CaCO}_{3}$ using the double diffusion variant of the silica hydrogel method. ${ }^{10}$ This method is suitable for reproducing crystallization conditions similar to natural environments such as sediments and soils ${ }^{11}$ where crystals form from confined aqueous solutions under limited mass transfer conditions. ${ }^{12-14}$ The goals of this research are (i) to unravel the effect of chromate anions on the polymorph selectivity of $\mathrm{CaCO}_{3}$, (ii) to evaluate the ability of the $\mathrm{CaCO}_{3}$ polymorph calcite, which is stable under normal Earth surface conditions, to incorporate chromate into its structure, and (iii) to understand the changes in the crystal properties of calcite induced by $\mathrm{Cr}(\mathrm{VI})$ incorporation.

\section{EXPERIMENTAL METHODS}

Gel Experiments. The crystallization experiments were performed in a double diffusion system. The experimental setup is shown in Figure 1. It consists of two vertical branches separated by a column of silica hydrogel. The vertical branches were filled with $0.5 \mathrm{M} \mathrm{CaCl}_{2}$ (branch A) and $0.5 \mathrm{M} \mathrm{Na}_{2} \mathrm{CO}_{3}$ solutions (branch $\mathrm{B}$ ). The silica hydrogel column was $125 \mathrm{~mm}$ long and $9 \mathrm{~mm}$ in diameter. The gel was prepared by adding $1 \mathrm{~N} \mathrm{HCl}$ to a sodium silicate solution $\left(\mathrm{Na}_{2} \mathrm{SiO}_{3}\right)$ (Merck $\mathrm{KGaA}$, sp. gr.: $\left.1.509 \mathrm{~g} / \mathrm{cm}^{3} ; \mathrm{pH}=11.2\right)$ until $\mathrm{pH}=5.5$ was reached. Different amounts of a $\mathrm{Na}_{2} \mathrm{CrO}_{4}$ solution were added to the mixture during the preparation of the gel. Thereby, the initial distribution of chromate within the gel column was homogeneous. Table 1 summarizes the composition of reagent solutions and the concentration of chromate in the hydrogel. Upon starting the experiments, the reactants are brought together by diffusion through the gel, and subsequently nucleation and crystal growth occur by chemical reaction within the gel column. Crystal growth was monitored by optical microscopy. Two months after 


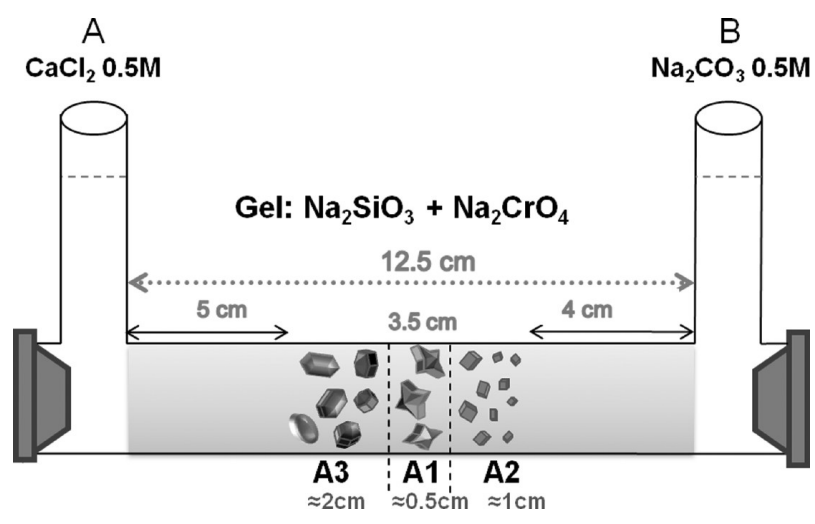

Figure 1. Experimental setup used for crystal growth. The sketch illustrates the different areas in which the crystallization region is divided considering the distribution of calcite crystal habits when chromatebearing gel was used. The crystallization starts in area 1. Subsequently, crystals form in $\mathrm{A} 1, \mathrm{~A} 2$ and $\mathrm{A} 3$.

nucleation, the experiments were stopped and the crystals were extracted by dissolving the gel in a $1 \mathrm{M} \mathrm{NaOH}$ solution. All experiments were carried out at $25^{\circ} \mathrm{C}$.

The physicochemical conditions within the gel at nucleation time were estimated following the protocol described by Katsikopoulos et al. ${ }^{15}$ In this approach, the concentration profiles of the reactants in the gel column can be calculated using a one-dimensional algorithm (eq 1), that is, assuming a linear diffusion model: ${ }^{12,16}$

$$
\begin{aligned}
C(d, t+\Delta t)= & \operatorname{mixf} \cdot C(d-\Delta d, t)+(1-2 \cdot \operatorname{mixf}) \cdot C(d, t) \\
& +\operatorname{mixf} \cdot C(d+\Delta d, t)
\end{aligned}
$$

where $C=$ reactant concentration, $d=$ distance from the source reservoir, $t=$ time, $\operatorname{mixf}=$ mixing factor , which depends on the porosity $(\varphi=1.19)$, the effective tortuosity of the gel $(\tau=0.969)$, and the diffusion coefficient of the reactant in water $(D w){ }^{17,18}$ The calculations were carried out using the geochemical code PHREEQC, version.2.13, ${ }^{19}$ which contains critical stability constants and diffusion coefficients of numerous solute species in water at $25^{\circ} \mathrm{C}$, its multicomponent-diffusion transport tool (MDT), and the PHREEQD.DAT database.

Morphological and Structural Characterization of $\mathrm{CaCO}_{3}$ Crystals. Crystals with representative morphologies were hand-picked and studied using scanning electron microscopy (JEOL JSM6400, $40 \mathrm{kV}$ ) equipped with a LINK Ex1 energy dispersive spectrometer.

Raman spectra of the samples were collected using a confocal Raman microscope (WITec alpha $300 \mathrm{R}$ ) equipped with a SHG Nd:YAG laser $(532 \mathrm{~nm}$, max. power $22.5 \mathrm{~mW})$ and a lens-based spectrometer. Elastically scattered photons were rejected by a long pass filter; that is, only the Stokes shifts were recorded. Using 600 and $1800 \mathrm{~mm}^{-1}$ diffraction gratings, the spectral resolution was 3.5 and $1.2 \mathrm{~cm}^{-1}$ per CCD-pixel, respectively. Spectra were recorded at selected positions with an integration time of 1,5 , and $10 \mathrm{~s}$ and 10 -fold averaging at $5 \mathrm{~mW}$. A $100 \times$ microscope objective (working distance $0.26 \mathrm{~mm}$, NA 0.90 ) was used for the measurements. On the samples, two areas were selected under the microscope and $2-3$ spots were analyzed from each area. The Raman bands of the $\mathrm{CaCO}_{3}$ polymorphs have been discussed by Wehrmeister et al. ${ }^{20}$ in detail. Thus, we follow their peak assignment.

Calcite crystals covering a wide range of morphologies and growth conditions were selected and further characterized by electron microprobe analysis and single crystal X-ray diffraction (SXRD). The calcite crystals were mounted in epoxy on glass slides, polished, carbon coated, and analyzed by a JEOL JXA 8900 microprobe. SXRD data were collected on a four-circle kappa diffractometer (Gemini, Oxford Diffraction, $50 \mathrm{kV}, 40 \mathrm{~mA}$ ) equipped with a CCD-detector (Atlas). For SXRD
Table 1. Concentrations of the Solutions Used in the Gel Experiments

\begin{tabular}{cccc} 
mixture & {$\left[\mathrm{CaCl}_{2}\right](\mathrm{M})$} & {$\left[\mathrm{Na}_{2} \mathrm{CrO}_{4}\right](\mathrm{M})$} & {$\left[\mathrm{Na}_{2} \mathrm{CO}_{3}\right](\mathrm{M})$} \\
$\mathrm{I}$ & 0.5 & & 0.5 \\
II & 0.5 & 0.10 & 0.5 \\
III & 0.5 & 0.15 & 0.5 \\
IV & 0.5 & 0.20 & 0.5 \\
\hline
\end{tabular}

measurements, the crystals were prepared by a pressurized air mortar to show a regular ellipsoidal form $(200 \mu \mathrm{m}$ in diameter $)$. The data were collected by a $\Phi$ scan with a step of $1^{\circ}$ in a $80 \mathrm{~mm}$ detector-crystal distance using $\mathrm{MoK}_{\alpha 1}$ radiation up to a $d$-spacing range of $0.7-0.8 \AA$. Data collection and reduction including absorption correction according to Clark and Reid ${ }^{21}$ were performed with the Oxford Diffraction data analysis software CrysAlisPro. Structure analyses and refinements were performed by direct methods and difference-Fourier synthesis, respectively, using SHELXL-97. ${ }^{22}$

\section{RESULTS AND DISCUSSION}

Influence of $\mathrm{Cr}(\mathrm{VI})$ on the $\mathrm{CaCO}_{3}$ Polymorph Selection and Crystallization Sequence. In all experiments, the first crystals observable with $400 \times$ magnification occurred after $\sim 240 \mathrm{~h}$. The crystals first appeared $\sim 7 \mathrm{~cm}$ from the calcium reservoir (branch A in Figure 1) within an area of $\sim 0.5 \mathrm{~cm}$ in length (A1). With time, the length of the crystallization region increased to about $3.5 \mathrm{~cm}$ after two months.

Although chromate caused no change in the initial nucleation time and the location of the first precipitate, the number, size, and morphology of the crystals differed with respect to experiments with pure gel. The distribution of crystal morphologies in $\mathrm{Cr}(\mathrm{VI})$-free experiments is depicted in Figure 2, while Figure 3 summarizes the results in chromate-bearing gels. According to the crystal morphology, three areas can be distinguished: A1, A2, A3. Crystallization occurs first in $\mathrm{A} 1(0.5 \mathrm{~cm})$ and subsequently in $\mathrm{A} 2(1 \mathrm{~cm})$ and $\mathrm{A} 3(2 \mathrm{~cm})$.

For $\mathrm{Cr}(\mathrm{VI})$-free experiments, rhombohedral single crystals occurred in all areas with slight morphological differences depending on their location (Figure 2). Crystals in A1 revealed dendritic branches (Figure $2 \mathrm{~b}$ ), while those in $\mathrm{A} 2$ and $\mathrm{A} 3$ evolved from hopper-shaped crystals (Figure 2c) to rhombohedra with flat faces (Figure 2a). Among the first nuclei in A1, a small number of spheres was also observed. These spheres dissolved shortly after their formation, while the rhombohedral crystals continued to grow. Irrespective of their morphology, all rhombohedral crystals revealed the same Raman spectrum (Figure 4a). We observed strong Raman bands at 156, 282, 711, and $1085 \mathrm{~cm}^{-1}$ which clearly indicate calcite. All spectral lines of the $\mathrm{CaCO}_{3}$ polymorphs and band-assignments are compiled in Table 2. Although no spheres could be recovered from the gel, the fact that they dissolved simultaneously with the growth of calcite crystals indicates a polymorph less stable than calcite, and according to their morphologies are most probably vaterite.

In chromate-bearing experiments, all areas contained rhombohedral single crystals. In A1 and A2, the rhombohedra were morphologically identical to those formed in $\mathrm{Cr}(\mathrm{VI})$-free gels (c.f., compare Figure 3, panels $\mathrm{c}$ and $\mathrm{g}$ to Figure 2, panels b and c). However, the morphology of the rhombohedral crystals in A3 differed remarkably. These crystals were yellow and grew elongated along their 3-fold axis with curved prism surfaces (Figure 3a,b). 


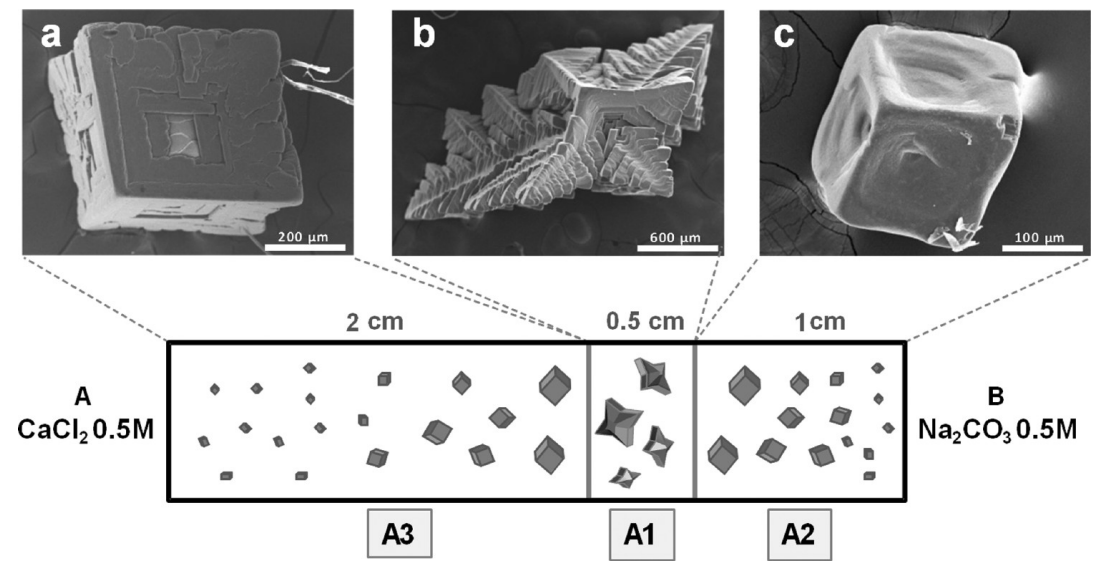

Figure 2. Typical sequences observed in $\mathrm{Cr}(\mathrm{VI})$-free experiments 2 months after the first nucleation. At this time, the crystals were retrieved from the gel.

Raman spectra of the crystals formed in A1 and A2 showed the same features as the spectrum in Figure $4 \mathrm{~b}$ confirming calcite. A Raman spectrum of an elongated rhombohedral crystal obtained from A3 is depicted in Figure 4c. The most prominent features of this spectrum also confirm calcite. However, additional peaks in the region between 800 and $1000 \mathrm{~cm}^{-1}$ cannot be assigned to calcite nor any other $\mathrm{CaCO}_{3}$ polymorph. The origin of these bands will be discussed later.

In $\mathrm{Cr}(\mathrm{VI})$-bearing gels, a significant amount of crystal aggregates formed in A1 and A2. These aggregates consisted of either radiating spherulitic (Figure 3e,f) or fibrous individuals (Figure 3d). Raman spectra from these aggregates are shown in Figure 5. All spectra collected from spherulitic individuals unambiguously show the typical vaterite triplet (symmetric stretching mode) at 1074, 1081, and $1094 \mathrm{~cm}^{-1}$ as well as the in-plane bending modes between 660 and $750 \mathrm{~cm}^{-1}$. Moreover, the various translational and rotational lattice modes of vaterite can be easily identified between 100 and $300 \mathrm{~cm}^{-1}$ (Figure 5a). In contrast, fibrous individuals revealed Raman spectra of aragonite as shown in Figure $5 \mathrm{~b}$.

In $\mathrm{A} 1$, the type of polymorph, number, and mean size of crystals were determined 12 days after their initial nucleation. The data are presented in Table 3. The number of crystals can be considered as representative of the nucleation density. In $\mathrm{Cr}$ (VI)-free gels, the first precipitate mainly consisted of calcite with less than $10 \%$ vaterite and no aragonite. In $\mathrm{Cr}(\mathrm{VI})$ containing gels, the suppression of calcite growth was clearly correlated with the chromate concentration. The nucleation density of vaterite and aragonite followed a trend opposite to that of calcite and strongly increased with the chromate concentration. At maximum chromate concentration, mainly vaterite and aragonite were found, whereas calcite represented merely $\sim 30 \%$. The mean size of the crystals also decreased with increasing chromate concentration. This decrease was especially evident in the case of calcite. In gels with $0.2 \mathrm{M}$ chromate, the size of calcite crystals was $50 \%$ of the size in control experiments.

The experiments show that chromate affected the nucleation density, the size, and the ratio of the precipitating polymorphs. In order to evaluate the extent of the chromate influence and to distinguish it from other parameters (such as supersaturation), information on the physicochemical conditions in the nucleation region at any time is required. Initially, the concentration of the reactants, $\mathrm{Ca}^{2+}$ and $\mathrm{CO}_{3}{ }^{2-}$, in the gel was zero and the distribution of chromate was homogeneous. Subsequently, counter-diffusion of reactants from the reservoirs and diffusion of chromate toward the columns induced concentration gradients within the column. If the diffusion of chemical species was progressing without crystallization, the gel column would become chemically homogeneous. The physicochemical evolution of the gel column can be modeled using PHREEQC, as explained in Section 2. Modeling of the system is limited to the time when the first precipitate is formed. Precipitates represent a sink for the reactants and affect diffusion. ${ }^{12}$ The simulations are summarized in Figure 6.

Maximum concentrations of $\mathrm{Ca}^{2+}$ and $\mathrm{CO}_{3}{ }^{2-}$ existed close to the respective reservoirs and progressively decreased with increasing distance (Figure 6a). The $\mathrm{CrO}_{4}{ }^{2-}$ concentration varied in the central part of the gel column to some degree and strongly decreased near the reactant reservoirs (Figure 6b). The $\mathrm{pH}$ profile resulted from the concentration profile. The $\mathrm{pH}$ was $\sim 10$ near the $\mathrm{Na}_{2} \mathrm{CO}_{3}$ reservoir, where the $\mathrm{CO}_{3}{ }^{2-}$ concentration was high, and decreased to 5.5 in the proximity of the $\mathrm{CaCl}_{2}$ reservoir (Figure 6c). Figure 6d shows the supersaturation profiles for all experiments. Independent of the initial concentration of chromate in the gel column, the supersaturation profiles show a maximum at $6.5 \mathrm{~cm}$ distance from the $\mathrm{CaCl}_{2}$ reservoir. The position of the first precipitate in the gel column was very close to this maximum and coincided with $\left[\mathrm{Ca}^{2+}\right] /\left[\mathrm{CO}_{3}{ }^{2-}\right]=1$ (Figure 6a). This is in good agreement with previous works. ${ }^{12,13,23-29}$ The maximum supersaturation (Figure 6d) decreased from $\beta_{\text {calcite }}=47$ for the $\mathrm{Cr}(\mathrm{VI})$ free experiment to $\beta_{\text {calcite }}=27$ for the $0.2 \mathrm{M}$ chromate-bearing gel due to an increasing complexation of calcium by chromate. It is worth to note that in all the cases supersaturation was calculated with respect to pure calcite. The lack of thermodynamic data on $\mathrm{Cr}(\mathrm{VI})$-bearing calcites made impossible to calculate the actual supersaturation of the solution with respect to calcites with different contents of $\mathrm{Cr}(\mathrm{VI})$. Nonetheless, it can be assumed that $\mathrm{Cr}(\mathrm{VI})$-bearing calcites are more soluble than pure calcite. Consequently, supersaturation values with respect to $\mathrm{Cr}(\mathrm{VI})$-bearing calcites should be lower than those presented in Figure 6d.

The differences in supersaturation cannot account for the differences in nucleation density, crystal sizes, and ratio of precipitating polymorphs. Considering the supersaturation profiles, the maximum nucleation density, the minimum crystal size, and the highest proportion of metastable polymoprhs would be expected in the $\mathrm{Cr}(\mathrm{VI})$-free experiment. The results showed the opposite (Table 3 ). It can be concluded that chromate inhibits the nucleation and growth of calcite and promotes the formation 


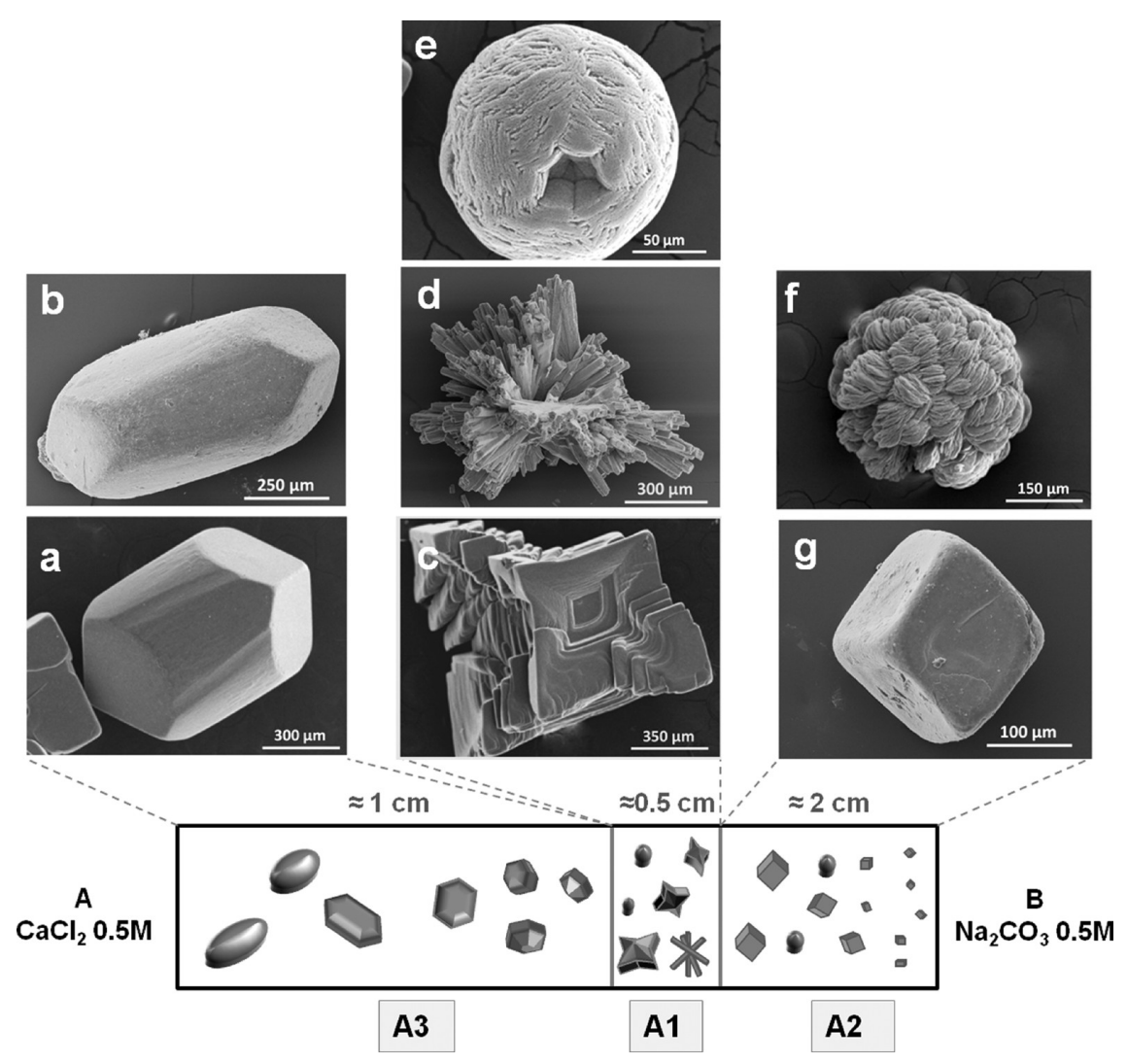

Figure 3. Typical sequence observed in the Cr-doped experiments 2 months after the first nucleation (when the crystals were retrieved from the gel).

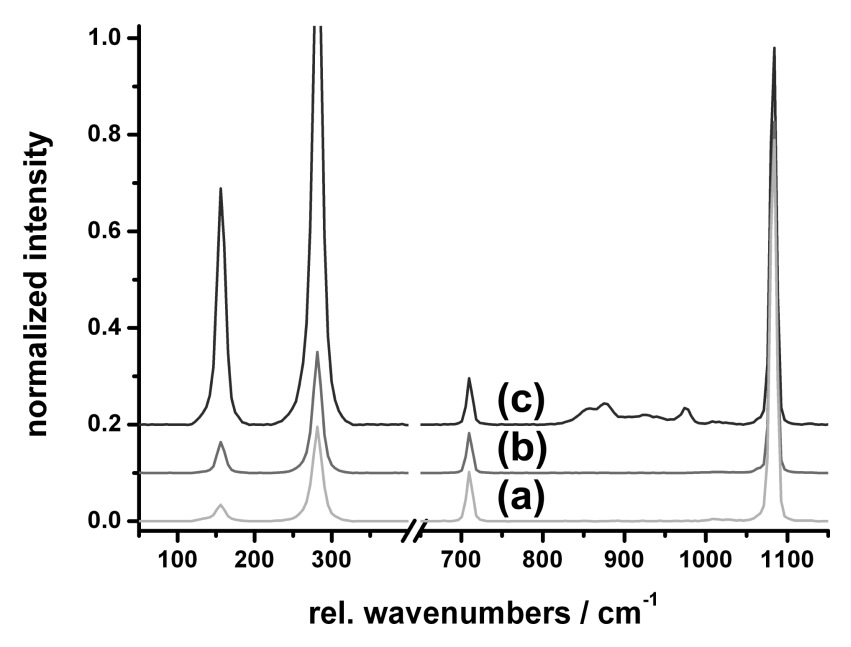

Figure 4. Raman spectra of crystals grown in the absence and in the presence of chromium. (a) Rhombohedral calcite crystals from A1, A2, and $\mathrm{A} 3$ in the control experiments. (b) Rhombohedral calcite crystals from $\mathrm{A} 1$ and $\mathrm{A} 2$ in the Cr-bearing experiments. (c) Elongated calcite crystals from $\mathrm{A} 3$ in the Cr-bearing experiments.

of metastable polymorphs. This is consistent with previous investigations. Hua et al. ${ }^{8}$ reported a direct correlation between the amount of vaterite in $\mathrm{CaCO}_{3}$ precipitates and the chromate concentration in an aqueous solution. The stabilization of metastable polymorphs, carbonate hydrates, or amorphous phases is not a unique property of chromate. Larsen ${ }^{28}$ and Ito ${ }^{29}$ related the formation of ikaite $\left(\mathrm{CaCO}_{3} \cdot 6 \mathrm{H}_{2} \mathrm{O}\right)$ to the presence of dissolved phosphate. It has also been suggested that the phosphate ion can stabilize biogenic amorphous calcium carbonate (ACC) in the caparace of some animals. ${ }^{30} \mathrm{Gal}$ et al. ${ }^{31}$ proposed that silicate ions play a similar role in the stabilization of biogenic ACC in cystholiths, the small calcified bodies produced by some plants. Kellermeier et al. ${ }^{32}$ obtained ACC nanospheres by inorganic precipitation from silicate-rich solutions. FernándezDíaz et al. $^{33}$ reported that high sulfate/carbonate ratios in aqueous solutions favors the formation of vaterite and inhibits its transformation into calcite. It is striking, however, that all these mentioned additives (including chromate) form tetrahedral anionic molecules.

Navrotsky ${ }^{34}$ pointed out that calcite, aragonite, and vaterite are close enough in free energy that small changes in their surface properties and/or concentration of impurities can give rise to stability crossovers. The effect of tetrahedral anionic molecules on the crystallization of $\mathrm{CaCO}_{3}$ might be related to the incorporation into their structures and/or to specific effects on the surface of the different polymorphs.

Isomorphic substitutions of anionic groups are not uncommon. For example, the $\mathrm{Ba}\left(\mathrm{SO}_{4}, \mathrm{CrO}_{4}\right)$ (Barite-hashemite) solid solution is complete. ${ }^{35}$ Substitutions of sulfate by selenate or arsenate were reported by Andara et al. ${ }^{18}$ In these cases, the geometry of the anionic groups is identical, which eases substitution energetically. Carbonate is triangular planar. However, there is evidence that small amounts of tetrahedral molecules can incorporate into the structure of $\mathrm{CaCO}_{3}$ phases. On the basis of the X-ray diffraction of natural calcites from biotic and abiotic origin, Busenberg and Plummer ${ }^{36}$ concluded that sulfate can substitute carbonate. Similar conclusions were made for synthetic $\mathrm{CaCO}_{3}$ precipitates. ${ }^{33}$ Frisia et al. ${ }^{37}$ corroborated the substitution of sulfate for carbonate groups in the calcite structure using synchrotron 
Table 2. Overview of the Raman Vibrations Observed for the $\mathrm{CaCO}_{3}$ Polymorphs ${ }^{a}$

$\begin{array}{lccc}\text { mode assignments } & \text { calcite } & \text { aragonite } & \text { vaterite } \\ \text { lattice modes } & 156,282 & 152,180, & 124,153, \\ & & 192,205, & 174,213, \\ & 247,260, & 268,277, \\ & & 271,283 & 301,332 \\ \text { in-plane } & 711 & 716 & 665,683, \\ \text { bending } & & & 738,744, \\ & & & 751 \\ \text { out-of-plane } & & & / \\ \text { bending } & & 1085 & 1074, \\ \text { symmetric } & & & 1081, \\ \text { stretching } & 1085 & & 1094\end{array}$

${ }^{a}$ Assignments follow Wehrmeister and co-workers. ${ }^{20}$ Peak positions are given in $\mathrm{cm}^{-1}$.

radiation-based techniques. Moreover, XANES and EXAFS analyses by Tang et al..$^{9}$ indicate that $\mathrm{Cr}$ in the calcite structure occurs as chromate, most probably substituting carbonate positions.

The Incorporation of Chromate into Calcite: Physicochemical Controlling Factors and Morphological Consequences. Some of the calcite crystals of the Cr-bearing experiments had shapes different from $\{104\}$ rhombohedra, a yellow shading, and additional bands in their Raman spectra. These features point toward an incorporation of chromate. In order to elucidate this possibility, different types of calcite crystals have been investigated further.

As explained above, all calcite crystals formed in $\mathrm{Cr}(\mathrm{VI})$-free experiments were rhombohedra bounded by the most stable $\{104\}$ faces. $^{38}$ Crystals in A1 showed signs of dendritic growth. This likely was a consequence of the high supersaturation in this region at least during nucleation and the initial stages of growth. The faces of rhombohedral crystals in A1 and A2 evolved from hopper to flat faces. Because crystals in A1 represented a sink for $\mathrm{Ca}^{2+}$ and $\mathrm{CO}_{3}{ }^{2-}$, the nucleation in $\mathrm{A} 2$ and $\mathrm{A} 3$ occurred at lower supersaturation levels. As growth progressed, supersaturation decreased due to the consumption of reactants. This lead to a change in the growth mechanism from a two-dimensional nucleation to a spiral growth. This change can account for the evolution of calcite crystals in A2 and A3. Similar explanations for the spatial and temporal evolution of the habit of calcite crystals grown in silica gel were provided by a number of authors. ${ }^{13,26,39}$

The morphology of the calcite crystals growing in A1 and A2 of the chromate-bearing gels can also be explained based on supersaturation evolution. However, supersaturation cannot account for the characteristics of calcite crystals in A3. The morphology of these crystals deviates from the normal $\{104\}$ rhombohedron. As shown in Figure 3a,b, these crystals are elongated along the $c$ axis, with curved surfaces in the prism region and terminated by $\{104\}$ faces. Their degree of elongation varies within a wide range, with length/width $(L / W)$ ratios between 1.1 and 2.2, independent from the initial chromate concentration in the gel although their mean length decreases with increasing initial chromate concentration $(0.85 \mathrm{~mm}$ for $0.1 \mathrm{M}$ and $0.52 \mathrm{~mm}$ for $0.2 \mathrm{M}$ chromate concentration). Moreover, within the same gel column, the $(L / W)$ ratio increases toward the $\mathrm{CaCl}_{2}$ reservoir (see calcite habit $\mathrm{A} 3 \mathrm{a}$ and $\mathrm{A} 3 \mathrm{~b}$ in Figure 3). These crystals show a yellow color whose intensity directly correlates

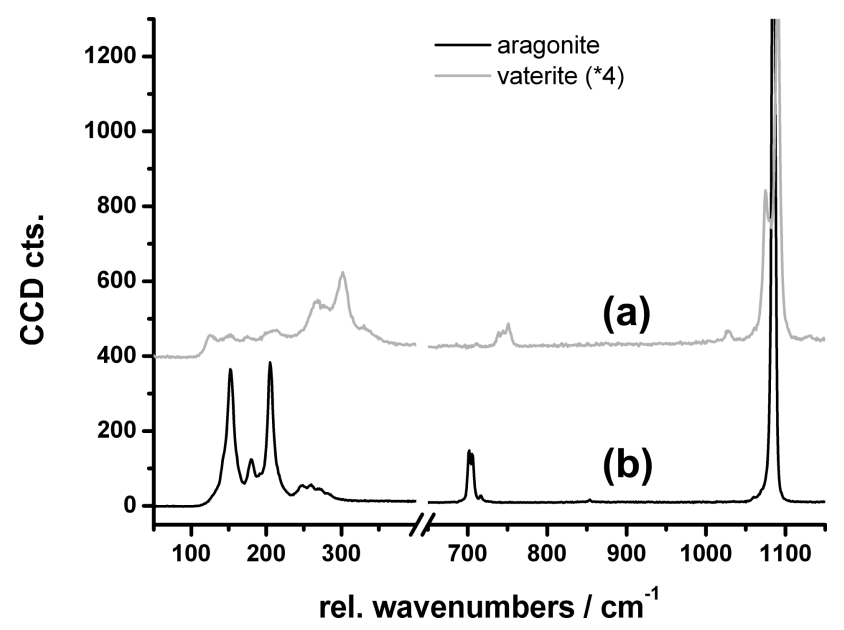

Figure 5. (a) The Raman spectrum taken from spherulitic aggregates is showing characteristic peaks of vaterite. (b) In contrast, the spectrum of fibrous aggregates matches with that of aragonite. In general, Raman scattering intensities in aragonite were around four times larger than in vaterite. The vaterite spectrum was maximized four times $\left({ }^{*} 4\right)$ for a better comparison.

with their $L / W$ ratio. The physicochemical parameters depicted in Figure 6 show that crystals in A2 and A3 form under similar supersaturations. The main differences depend on the ratio between the relevant chemical species and $\mathrm{pH}$. Because $\mathrm{pH}$ controls the distribution of dissolved carbon between $\mathrm{CO}_{3}{ }^{2-}$, $\mathrm{HCO}_{3}{ }^{-}$, and $\mathrm{H}_{2} \mathrm{CO}_{3}$, the $\mathrm{CrO}_{4}{ }^{2-} / \mathrm{CO}_{3}{ }^{2-}$ ratio was low in the region of the gel column where the $\mathrm{pH}$ was high, that is, close to the $\mathrm{Na}_{2} \mathrm{CO}_{3}$ reservoir (Figure 1), and vice versa. Figure 7 shows the distribution of $\mathrm{CrO}_{4}{ }^{2-} / \mathrm{CO}_{3}{ }^{2-}$ ratio values along the gel column for the $0.2 \mathrm{M}$ bearing chromate experiments at nucleation time. The inset shows the value of this ratio in the crystallization region $(5-8.5 \mathrm{~cm})$. As can be seen, yellow elongated calcite crystals only appeared in the region where $\mathrm{CrO}_{4}{ }^{2-} / \mathrm{CO}_{3}{ }^{2-}>70$. Moreover, within $\mathrm{A} 3$, the $L / W$ ratio varied between 1.1 and 1.25 where $360>\mathrm{CrO}_{4}{ }^{2-} / \mathrm{CO}_{3}{ }^{2-}>70$ (A3a) and between 2 and 2.2 where $\mathrm{CrO}_{4}{ }^{2-} / \mathrm{CO}_{3}{ }^{2-}>360(\mathrm{~A} 3 \mathrm{~b})$. Therefore, it can be concluded that the $\mathrm{CrO}_{4}{ }^{2-} / \mathrm{CO}_{3}{ }^{2-}$ ratio was the factor that most strongly controlled the variation in habit when calcite formed in the presence of chromate.

The morphology of calcite crystals in $\mathrm{A} 3$ of chromate-bearing gels was similar to that observed with $\mathrm{SO}_{4}{ }^{2-}$ or $\mathrm{HPO}_{4}{ }^{2-}$ as additives. $^{33,40,41}$ Parker et al. ${ }^{42}$ and Titiloye et al. ${ }^{43}$ used molecular dynamics to predict the effect of $\mathrm{HPO}_{4}{ }^{2-}$ on calcite morphology. According to these authors, hydrophosphate selectively segregates on the $\{100\}$ faces due to a combination of strong binding and minimal steric hindrance. As a result, the predicted morphology is a first-order prism capped with rhombohedral end faces. A similar mechanism can explain the effect of the chromate on calcite morphology.

Raman spectra of elongated yellow calcites from gels with different initial chromate concentrations are shown in Figure 8. In addition to those bands characteristic for calcite (Table 2), all spectra show weak bands between 850 and $925 \mathrm{~cm}^{-1}$. The inset in Figure 8 shows a close up of this region with the main vibrational modes for chromatite $\left(\mathrm{CaCrO}_{4}\right)$ for comparison. The chromatite spectrum was obtained from a natural sample.

Among the $\mathrm{CaCO}_{3}$ polymorphs, only aragonite reveals a peak at approximately $853 \mathrm{~cm}^{-1}$. For calcite, such a peak is not 
Table 3. Crystal Density (cd) and Mean Size of Calcite (C), Vaterite (V), and Aragonite (A) Individuals Formed in A1 Measured 12 Days after the Formation of the First Nuclei

\begin{tabular}{lcccccc}
\multicolumn{7}{c}{ AREA 1 (12 days after nucleation) } \\
\hline & $C-\mathrm{cd}^{a}$ & $C-\operatorname{size}(\mathrm{mm})$ & $V-\mathrm{cd}^{a}$ & $V-$ size $(\mathrm{mm})$ & $A-\mathrm{cd}^{a}$ & $A-\operatorname{size}(\mathrm{mm})$ \\
pure system & 17 & $1.25 \times 0.75$ & 2 & $0.75 \varnothing$ & 5 & $0.25 \varnothing$ \\
$0.10 \mathrm{M} \mathrm{Cr}$ & 15 & $1 \times 0.5$ & 4 & $0.25 \varnothing$ & $0.5 \times 0.2$ \\
$0.15 \mathrm{M} \mathrm{Cr}$ & 12 & $0.62 \times 0.5$ & 6 & $0.2 \varnothing$ & 12 \\
$0.20 \mathrm{M} \mathrm{Cr}$ & 10 & $0.5 \times 0.37$ & 10 & & $0.3 \times 0.12$ \\
${ }^{a}$ Number of crystals observable with $400 \times$ magnification. & & & \\
\hline
\end{tabular}

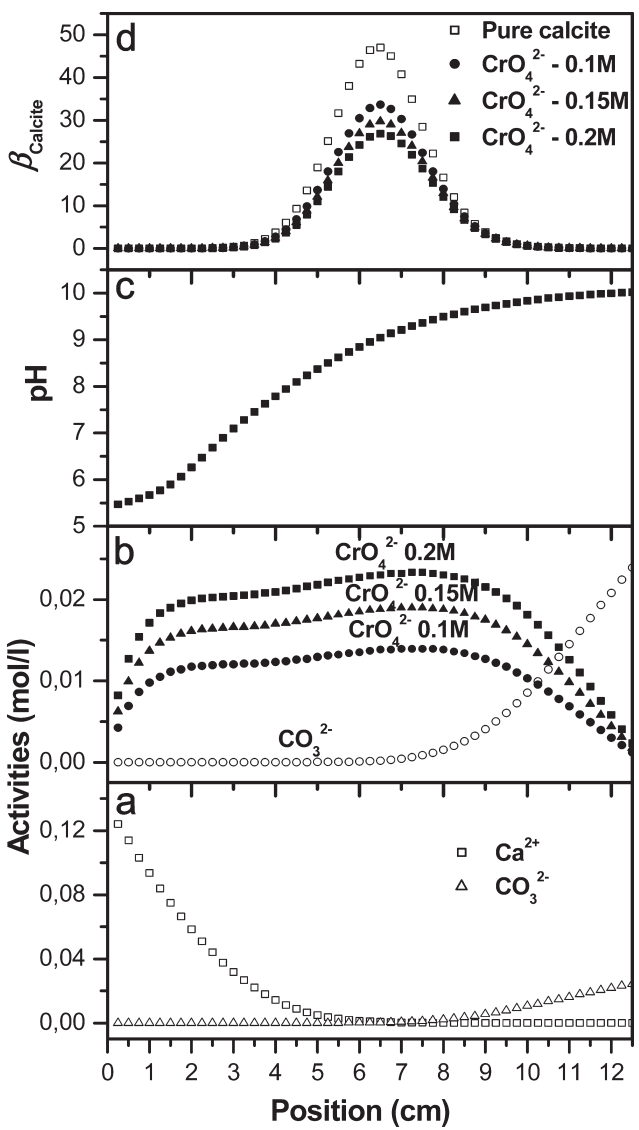

Figure 6. Activity profiles at the moment of nucleation of the first crystal modeled using PHREEQC. (a) Concentration profiles of $\mathrm{Ca}^{2+}$ and $\mathrm{CO}_{3}{ }^{2-}$ ions, (b) concentration profiles of $\mathrm{CO}_{3}{ }^{2-}$ and $\mathrm{CrO}_{4}{ }^{2-}$ ions, (c) $\mathrm{pH}$ profile, and (d) supersaturation with respect to calcite along the diffusion column.

expected. However, this vibrational mode also corresponds to the most prominent band of chromatite at $875 \mathrm{~cm}^{-1}\left(\mathrm{CrO}_{4}\right.$ symmetric stretching). Some additional weak bands are also present. Wilkins $^{44}$ reported that the Raman spectrum of crocoite gives three bands in the $\mathrm{CrO}$ stretching region at 825,838 , and $853 \mathrm{~cm}^{-1}$. Frost ${ }^{45}$ showed the Raman spectra of the $\mathrm{CrO}$ stretching region of some chromate-bearing minerals with a varying position from 825 to $972 \mathrm{~cm}^{-1}$ depending on the mineral. In our experiments, we observed three main bands at 858,875 , and $974 \mathrm{~cm}^{-1}$. The first two bands are in agreement with the peak positions reported by Frost ${ }^{45}$ and, subsequently, the new bands can be a consequence of the incorporation of $\mathrm{Cr}(\mathrm{VI})$ into the calcite structure as chromate groups. Furthermore, Wang

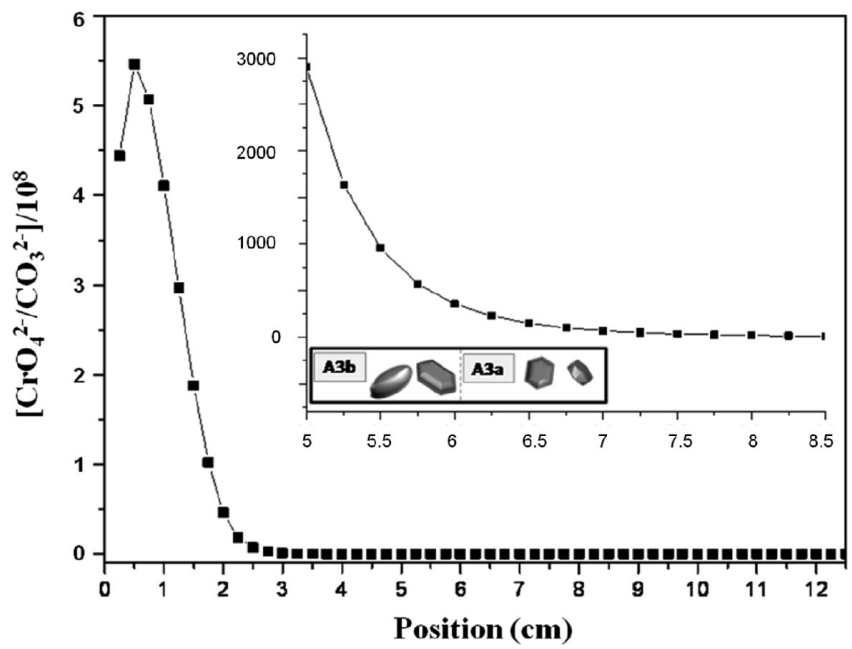

Figure 7. Distribution of the $\mathrm{CrO}_{4}{ }^{2-} / \mathrm{CO}_{3}{ }^{2-}$ ratio along the gel column for the $0.2 \mathrm{M}$ bearing chromate experiments at nucleation time. The inset shows the value of this ratio in the crystallization region.

et $\mathrm{al}^{46}$ conducted a Raman spectroscopic study to distinguish the chromate species on Cr-MCM-41 synthesized by direct hydrothermal synthesis. There, the color of the samples was pale green and it changed to pale yellow after the calcinations suggesting the change of the oxidation state of the $\mathrm{Cr}$ species from $\mathrm{Cr}^{3+}$ to $\mathrm{Cr}^{6+}$. The band at $980 \mathrm{~cm}^{-1}$ was assigned to the $\mathrm{Cr}-\mathrm{O}$ vibration stretching of the dehydrogenated monochromate species $\left(\mathrm{CrO}_{4}^{-2}\right)$. Thus, the third more intense band that we observed in our data can also be correlated with the presence of $\mathrm{Cr}(\mathrm{VI})$ incorporated into the calcite structure. This is supported by the fact that the intensity of the new bands correlates with the initial content of chromate in the growth medium.

Pale yellow calcite crystals were chosen for SXRD studies, and these were compared to pure calcite. Reconstructed reciprocal planes of all data sets display no forbidden reflections which do not belong to $R \overline{3} c$, except for weak reflections due to $\lambda / 2$ at small Bragg angles (Figure 9).

In order to check the hypothesis that chromate was incorporated into the yellow calcite crystals, their structures were determined, refined, and compared to the refined structure model of pure calcite: $\mathrm{C}$ sites for each structures could be easily found by the difference Fourier analysis, after the determination of $\mathrm{Ca}$ and $\mathrm{O}$ positions by direct methods. In order to prove the substitution of $\left(\mathrm{CrO}_{4}\right)^{4-}$ for $\left(\mathrm{CO}_{3}\right)^{2-}$, in the last cycle of refinement, the occupancy parameter of $\mathrm{C}$ was calculated using fixed anisotropic atomic displacement parameters (ADPs in $\left[\AA^{2}\right]$ ) with values that had been obtained by analyzing our SXRD 
data of pure calcite: $U_{11}=0.01074\left[\AA^{2}\right] ; U_{22}=0.01074\left[\AA^{2}\right] ; U_{33}=$ $0.01037\left[\AA^{2}\right] ; U_{12}=0.00537\left[\AA^{2}\right]$. The resulting occupancy parameters showed more than $100 \%$ occupancies, indicating partial substitution of $\mathrm{Cr}(\mathrm{VI})$ for $\mathrm{C}$. From the resulting occupancies, the weight percentages of $\mathrm{Cr}(\mathrm{VI})$ between $2667 \mathrm{ppm}$ and $6667 \mathrm{ppm}$ could be estimated as given in Table 4. These values cannot be the correct portion of $\left(\mathrm{CrO}_{4}\right)^{4-}$ substituting for $\left(\mathrm{CO}_{3}\right)^{2-}$ in our yellow calcite crystals due to the fixed ADPs in the refinements. However, the higher occupancy parameters refined for yellow calcite structures compared to that of the pure calcite indirectly point to the incorporation of $\left(\mathrm{CrO}_{4}\right)^{4-}$ in the calcite lattice.

Electron microprobe analyses of the elongated yellow samples (area A3) obtained from the chromium bearing experiments yielded similar results as those derived from the SXRD study. The chromate concentration obtained for those samples varied depending on the $\mathrm{Cr}$ concentration in the growth medium, and it was $(1900 \pm 300) \mathrm{ppm},(3800 \pm 500) \mathrm{ppm}$, and $(5900 \pm 400)$ ppm for calcite crystals grown in the presence of $0.1 \mathrm{M}, 0.15 \mathrm{M}$, and $0.2 \mathrm{M}$ of chromium. Both SXRD and microprobe results indicate a direct correlation between the $\mathrm{Cr}(\mathrm{VI})$ content of the yellow calcites and the initial chromate concentration in the gel. According to our results, chromate was incorporated into the calcite structure isomorphically by substituting carbonate. This substitution was restricted by the different geometry of the

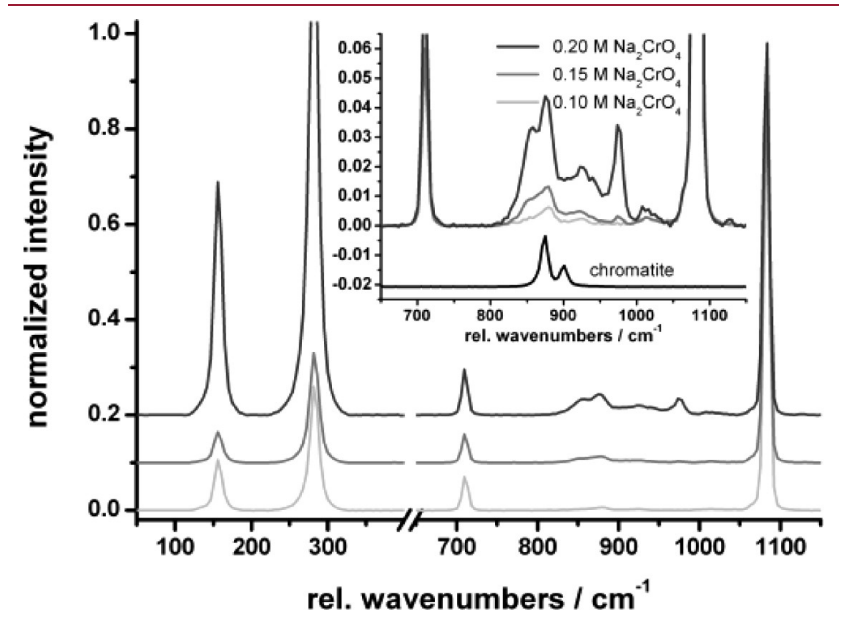

Figure 8. Comparison of the Raman spectra corresponding to calcite crystals with deep yellow color from the experiment with $0.1,0.15$, and $0.2 \mathrm{M} \mathrm{Na}_{2} \mathrm{CrO}_{4}$ in the gel. The inset shows a close up view of the chromate induced peaks. chromate molecule and the carbonate group, which likely caused local strain.

$\left[\mathrm{CrO}_{4}{ }^{2-}\right] /\left[\mathrm{CO}_{3}{ }^{2-}\right]$ ratios plotted in Figure 7 exclusively represent the values at nucleation time. As crystallization progresses, this ratio changes due to the coupling between mass transfer from and toward the reservoirs and reagent consumption by the growing crystals. Although the lack of information on the extension of this coupling makes it impossible to obtain reliable $\left[\mathrm{CrO}_{4}{ }^{2-}\right] /\left[\mathrm{CO}_{3}{ }^{2-}\right]$ ratios in the region of the gel column and at the time of calcite crystal formation, we can use the $\left[\mathrm{CrO}_{4}{ }^{2-}\right] /\left[\mathrm{CO}_{3}{ }^{2-}\right]$ ratios at nucleation time as reference values. By comparing $\left[\mathrm{CrO}_{4}{ }^{2-}\right] /\left[\mathrm{CO}_{3}{ }^{2-}\right]$ ratios in the calcite crystals
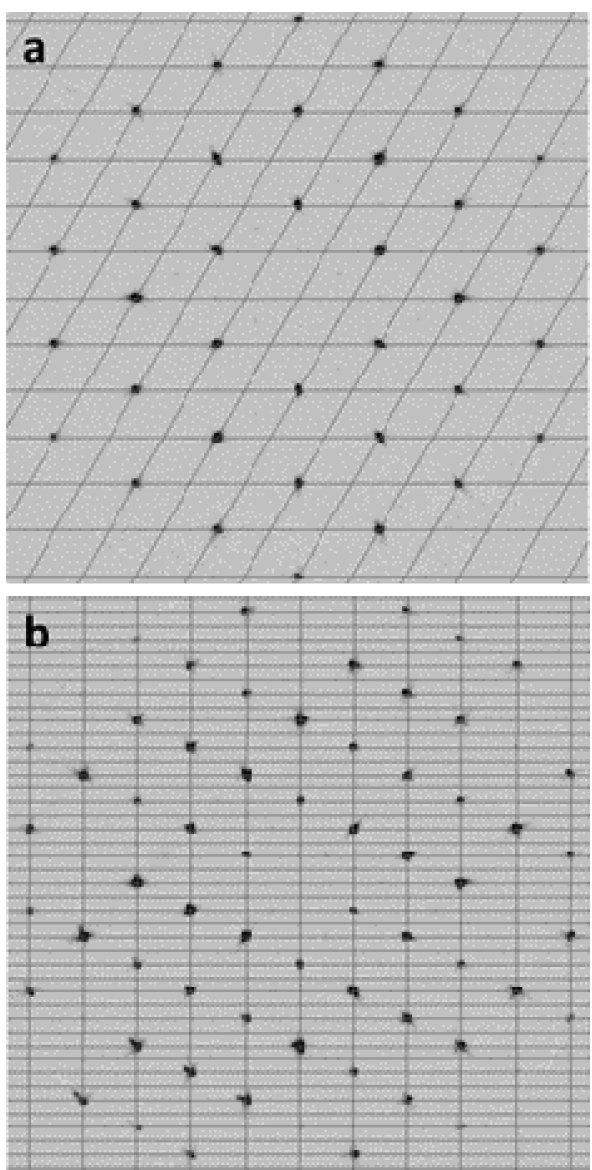

Figure 9. (a) Reconstructed reciprocal $h k 0$ and (b) $h 0 l$ planes from SXRD data.

Table 4. Refined Structure Parameters of the Pure and Yellow Crystals Obtained from the Area A3 in the Cr-Doped Experiments

\begin{tabular}{|c|c|c|c|c|}
\hline refined parameter & $\mathrm{CaCO}_{3}$ pure & $\mathrm{CaCO}_{3}-\mathrm{Cr} 0.1 \mathrm{M}$ & $\mathrm{CaCO}_{3}-\mathrm{Cr} 0.15 \mathrm{M}$ & $\mathrm{CaCO}_{3}-\mathrm{Cr} 0.20 \mathrm{M}$ \\
\hline$a[\AA]$ & $4.9885(1)$ & $4.9866(2)$ & $4.9869(2)$ & $4.9864(2)$ \\
\hline$c[\AA]$ & $17.0729(3)$ & $17.0613(6)$ & $17.0554(8)$ & $17.0592(6)$ \\
\hline$V\left[\AA^{3}\right]$ & 367.9 & 367.4 & 367.3 & 367.3 \\
\hline \# unique reflections & 153 & 110 & 108 & 153 \\
\hline$R_{\text {int }}[\%]$ & 3.72 & 1.16 & 1.84 & 2.25 \\
\hline$w R_{2}[\%]^{a}$ & 4.36 & 4.03 & 4.01 & 3.82 \\
\hline goodness-of-fit & 1.34 & 1.33 & 1.31 & 1.32 \\
\hline occupancy for the $C$ position $[0.1667 \cong 100 \%]$ & 0.1667 & $0.168(2)$ & $0.169(2)$ & $0.170(1)$ \\
\hline amount $\mathrm{Cr}$ at the site for $\mathrm{C}[\mathrm{ppm}]$ & 0 & $2667(32)$ & $4667(55)$ & $6667(39)$ \\
\hline
\end{tabular}

${ }^{a}$ Weight $=1 /\left[\sigma^{2}\left(F_{\mathrm{o}}{ }^{2}\right)+\left(a^{*} P\right)^{2}+b^{*} P\right]$ where $P=\left(\operatorname{Max}\left(\mathrm{F}_{\mathrm{o}}{ }^{2}, 0\right)+2{ }^{*} F_{\mathrm{c}}{ }^{2}\right) / 3$; with the observed and calculated structure factor $F_{\mathrm{o}}$ and $F_{\mathrm{c}}$, respectively, and the refined $a$ and $b$ values during the analysis. 
(in ppm) and in the fluid (in $\mathrm{mM}$ ), apparent $\mathrm{Cr}(\mathrm{VI})$ partitioning coefficients $\left(K_{d}\right)$ are obtained, according to the following equation: ${ }^{36}$

$$
K_{\mathrm{d}}=\left[\mathrm{CrO}_{4}^{2-} / \mathrm{CO}_{3}^{2-}\right]_{\text {solid }} /\left[\mathrm{CrO}_{4}^{2-} / \mathrm{CO}_{3}^{2-}\right]_{\text {solution }}
$$

The average calculated apparent partition coefficient is $\sim 10$ in all the experiments. However, apparent partition coefficients strongly vary in a given experiment, with values ranging from $\sim 2$, in the region where the calcite and the aqueous solution $\left[\mathrm{CrO}_{4}{ }^{2-}\right] /\left[\mathrm{CO}_{3}{ }^{2-}\right]$ ratios are lower (region A3a in Figure 7 ) to $\sim 20$, in the region where the calcite and the aqueous solution $\left[\mathrm{CrO}_{4}{ }^{2-}\right] /\left[\mathrm{CO}_{3}{ }^{2-}\right]$ ratios are higher (region A3b in Figure 7$)$. It is important to note that the partitioning coefficients calculated in this way necessarily are inaccurate because their value can be strongly affected by factors such as supersaturation, growth rate, and $\mathrm{Cr}$ (VI) depletion during growth, which cannot be controlled. Moreover, the distribution of $\mathrm{Cr}(\mathrm{VI})$ in the calcite crystals is not homogeneous. However, it is striking that the average apparent partition coefficient reported in this work $(\sim 10)$ coincides with that obtained by Tang et $\mathrm{al}^{9}$ in batch coprecipitation experiments when $[\mathrm{Cr}]_{\text {solution }}>10 \mathrm{mM}$. Therefore, it can be concluded that our result reasonably estimates $\mathrm{Cr}(\mathrm{VI})$ partitioning in strongly contaminated media when mass transfer is restricted.

\section{CONCLUSIONS}

The presence of a toxic pollutant such as $\mathrm{Cr}(\mathrm{VI})$ in the crystallization medium has an important influence on both the nucleation and the growth of $\mathrm{CaCO}_{3}$. Regarding the nucleation, it can be concluded that $\mathrm{Cr}(\mathrm{VI})$ (i) promotes the formation of vaterite and aragonite, which form in a higher proportion in $\mathrm{Cr}(\mathrm{VI})$-bearing experiments compared to $\mathrm{Cr}(\mathrm{VI})$-free experiments and (ii) reduces the nucleation density of calcite proportionally to the $\mathrm{Cr}$ concentration in the medium. Regarding the influence of $\mathrm{Cr}(\mathrm{VI})$ on the growth of $\mathrm{CaCO}_{3}$ polymorphs, we observed that with an increasing concentration of $\mathrm{Cr}(\mathrm{VI})$ in the medium (i) the mean size of single crystals and aggregates decreases, (ii) the habit of calcite crystals changes from $\{104\}$ to forms elongated along the $c$-axis, and (iii) the amount of incorporated $\mathrm{Cr}$ increases. This incorporation is evidenced by the appearance of additional vibrational bands in the Raman spectra. The location of these bands is consistent with the substitution of carbonate groups by chromate groups.

The coprecipitation of chromate with calcium carbonate is a likely process when calcite forms in media strongly contaminated by chromate, especially when mass transfer is restricted. This incorporation can significantly affect the biological availability of this pollutant in natural environments. Moreover, the apparent partitioning coefficients of $\mathrm{Cr}(\mathrm{VI})$ into calcite determined in this work suggest that $\mathrm{CaCO}_{3}$ precipitation processes have the potential to significantly influence the fate of this pollutant in natural environments.

\section{AUTHOR INFORMATION}

\section{Corresponding Author}

*Tel: +34-91-394-4884. Email: nsanchez@geo.ucm.es.

\section{ACKNOWLEDGMENT}

N.S.-P. gratefully acknowledges the fellowship from the Humboldt Foundation. Financial support has been provided by Projects
CGL2007-65523-C02-01 and CGL2010-20134-C02-01 (Spanish Ministry of Science and Innovation). We thank the Microscopy Centre of the Complutense University for technical assistance and support. We are also grateful to Robert W. Stark (TU Darmstadt) for enabling Raman measurements and Rupert Hochleitner (Mineralogische Staatssammlung, München) for providing the chromatite sample.

\section{REFERENCES}

(1) Katz, S. A.; Salem, H. In The Biological and Environmental Chemistry of Chromium; VCH: New York, 1994.

(2) Traina, S. J.; Laperche, V. Proc. Natl. Acad. Sci. U. S. A. 1999, 96, 3365-3371.

(3) Prieto, M.; Cubillas, P.; Fernandez-Gonzalez, A. Geochim. Cosmochim. Acta 2003, 67, 3859-3869.

(4) Pérez-Garrido, C.; Fernández-Díaz, L.; Pina, C. M.; Prieto, M. Surf. Sci. 2007, 601, 5499-5509.

(5) Godelitsas, A.; Astilleros, J.M .; Hallam, K.; Harissopoulos, S.; Putnis, A. Environ. Sci. Technol. 2003, 37, 3351-336.

(6) Garelick, H.; Dybowska, A.; Valsami-Jones, E.; Priest, N. D. J. Soils Sediments 2005, 5, 182-190.

(7) Sneedon, I. R.; Orueetxebarria, M.; Hodson, M. E.; Schofield, P. F.; Valsami-Jones, E. Environ. Pollut. 2006, 144, 816-825.

(8) Hua, B.; Deng, B. L.; Thorton, E. C.; Yang, J.; Amonette, J. E. Water, Air, Soil Pollut. 2007, 179, 381-390.

(9) Tang, Y. Z.; Elzinga, E. J.; Lee, Y. J.; Reeder, R. J. Geochim. Cosmochim. Acta 2007, 71, 1480-1493.

(10) Henisch, H. K. In Crystals in Gels and Liesegang Rings; Cambridge University Press: New York, 1988.

(11) Putnis, A.; Prieto, M.; Fernández-Díaz, L. Geol. Mag. 1995, 132 (1), 1-13.

(12) Henisch, H. K.; García-Ruiz, J. M. J. Cryst. Growth 1986, 76, 203-211.

(13) Prieto, M.; Fernández-Díaz, L.; López-Andrés, S. J. Cryst. Growth 1989, 98, 447-460.

(14) Sánchez-Pastor, N.; Pina, C. M.; Fernández-Díaz, L. Chem. Geol. 2006, 225, 266-277.

(15) Katsikopoulos, D.; Fernández-González, A.; Prieto, M. Min. Mag. 2009, 73, 269-284.

(16) Appelo, C. A. J.; Postma, D. In Geochemistry, Groundwater and Pollution, 2nd ed.; A. A. Balkema Publishers: Leiden, The Netherlands, 2005.

(17) Oelkers, E. In Physical and Chemical Properties of Rocks and Fluids for Chemical Mass Transfer Calculations; Lichtner, P. C., Steefel, C. I. Oelkers, E. H., Eds.; Reviews in Mineralogy, Mineralogical Society of America: Chantilly, Virginia, USA, 1996; Vol. 34, p 131.

(18) Andara, A.; Heasman, D. M.; Fernández-González, A.; Prieto, M. Cryst. Growth Des. 2005, 5, 1377-1378.

(19) Parkhurst, D. L.; Appelo, C .A . J. In User's guide to PHREEQC (Version 2): A Computer Program for Speciation, Batch-Reaction, OneDimensional Transport and Inverse Geochemical Calculations; U.S. Geological Survey Water Resources Investigations Report; U.S. Geological Survey: Washington, DC, 2003.

(20) Wehrmeister, U.; Soldati, A. L.; Jacob, D. E.; Häger, T.; Hofmeister, W. J. Raman Spectrosc. 2010, 41, 193-201.

(21) Clark, R. C.; Reid, J. S. Acta Crystallogr. 1995, A51, 887-897.

(22) Sheldrick, G. M. In SHELXL-93, Program for the Refinement of Crystal Structures; University of Göttingen: Göttingen, Germany, 1993.

(23) Prieto, M.; Putnis, A.; Fernández-Díaz, L. Geol. Mag. 1990, 127, 485-617.

(24) Prieto, M.; Fernández-Díaz, L.; López-Andrés, S. J. Cryst. Growth 1991, 108, 770-778.

(25) Prieto, M.; Putnis, A.; Fernández-Díaz, L.; López-Andrés, S. J. Cryst. Growth 1994, 142, 225-235.

(26) Putnis, A.; Prieto, M.; Fernández-Díaz, L. Geol. Mag. 1995, $132,1-13$. 
(27) Fernández-Díaz, L.; Putnis, A.; Prieto, M.; Putnis, C. V. J. Sediment. Res. 1996, 66, 482-491.

(28) Larsen, D. J. Sediment. Res. 1994, 64, 593-603.

(29) Ito, T. J. Min. Pet. Econ. Geol. 1996, 91, 209-219.

(30) Al-Sawalmih, A.; Li1, C.; Siegel, S.; Fratzl, P.; Paris, O. Adv. Mater. 2009, 21, 4011-4015.

(31) Gal, A.; Weiner, S.; Addadi, L. J. Am. Chem. Soc. 2010, $132,13208-13211$.

(32) Kellermeier, M.; Melero-García, E.; Glaab, F.; Klein, R.; Drechsler, M.; Rachel, R.; García-Ruiz, J. M.; Kunz, W. J. Am. Chem. Soc. 2010, 132 (50), 17859-66.

(33) Fernández-Díaz, L.; Fernández-González, A.; Prieto, M. Geochim. Cosmochim. Acta 2010, 74, 6064-6076.

(34) Navrotsky, A. Proc. Natl. Acad. Sci. U. S. A. 2010, 101 (33), 12096-12101.

(35) Prieto, M.; Fernández-González, A.; Putnis, A.; FernándezDíaz, L. Geochim. Cosmochim, Acta. 1997, 61 (16), 3383-3397.

(36) Busenberg, E.; Plummer, N. Geochim. Cosmochim. Acta 1985, 49, 713-725.

(37) Frisia, S.; Borsato, A.; Fairchild, I. J.; Susini, J. Earth Planet. Sci. Lett. 2005, 235, 729-740.

(38) Heijnen, W. M. M. N. Jb. Miner. Mh. 1985, 8, 357-362.

(39) Fernández-González, A.; Prieto, M.; Putnis, A.; López-Andrés, S. Mineral. Mag. 1999, 63, 331-343.

(40) Fernández-Díaz, L.; Pina, C. M.; Astilleros, J. M.; SánchezPastor, N. Am. Mineral. 2009, 94, 1223-1234.

(41) Suzuki, T.; Inomata, S.; Sawada, K. J. Chem. Soc. Faraday Trans. 1986, 82, 1733-1743.

(42) Parker, S. C.; Titiloye, J. O.; Watson, G. W. Phil. Trans. R. Soc. Lond. A 1993, 344, 37-44.

(43) Titiloye, J. O.; Parker, S. C.; Mann, S. J. Cryst. Growth 1993, 131, 533-545.

(44) Wilkins, R. W. T. Min. Mag. 1971, 38, 249-1971.

(45) Frost, R. L.; Weier, M. Neues Jahrb. Mineral., Monatsh 2004, 12, 575-594.

(46) Wang, Z.; Wilson, G. F.; Griffith, L. C. J. Biol. Chem. 2002, 277 (27), 24022-24029. 